REVIEW

\title{
Age assessment: time for progress?
}

\section{A Michie}

Arch Dis Child 2005;90:612-613. doi: 10.1136/adc.2003.041921

Care provided to unaccompanied asylum seeking minors in Britain is currently compromised by the issue of age assessment. Existing guidelines are rarely followed leading to striking defects in the protection for a high risk group of children and adolescents.

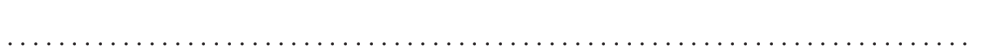

F rom the perspective of child protection those under 18 are cared for, educated, and protected when required by Social Services. This is a duty and not a moral gift of sympathy, enshrined in the Children Act (Sections 17 and 20 ). For national agencies and current budgets a great deal therefore appears to depend on a rigid definition of whether an individual is 18 years of age or younger. A growing challenge to this watershed is provided by those seeking asylum in the United Kingdom who are unaware of their exact date of birth, or travelling without appropriate identity papers or perhaps simply not accepted as minors by the Immigration Services. With the changes in immigration dispersal in 1999, these clients are now placed across the country. Declared numbers of unaccompanied asylum seekers to the United Kingdom known to be under the age of 18 has risen from 2000-4000 in the years 1999-2000 to over 6000 in 2002 and 2003. Most of these children have come from Africa, Asia, and the Middle East. At the same time there has been a parallel increase in minors accompanied by an adult, whether relative or friend. ${ }^{1}$ Recent events on the Indian Ocean's rim may radically alter this pattern.

If the age of minors in this position is not determined, and they are not given the benefit of the doubt as recommended by United Nations High Commission for Refugees, the British Home Office, or Social Services, a succession of abuses is encountered. They will be interviewed and taken to court without assistance, housed or detained with adults, and on occasions may be made homeless. As a group they are known to be needy and susceptible to abuse from others; such management compounds their suffering in direct contravention of national and international guidelines. A lack of clear age assessment additionally feeds the trafficking of children into or through the UK.

It is difficult to determine just how many minors are failed by current provisions as the collection of such figures is complex and prone to error. The numbers of children cared for by local government has not increased in parallel to arrivals, remaining fairly static at 2000-3000 in 2002 and 2003. ${ }^{2}$ In 2003, a Refugee Council survey revealed 268 unaccompanied minors were held in asylum detention centres (personal communication). In the same year an estimated 3000 individuals were made homeless when the National Asylum Seekers Service ceased payments to their hostels: a proportion of these were under 18 years of age, never having received age assessments. Operation Paladin carried out in Heathrow Airport for the last three months of 2003 showed problems with children who arrive "accompanied" or with letters of "transfer of parental responsibility". Not all such arrivals could be traced; such tracking is a central component of child protection. The workloads of charitable groups such as the Refugee Council have risen; in 2003 this service was referred an average of 148 cases a month for dispute of age, over double the numbers of 2001 (personal communication).

\section{CURRENT APPROACHES}

A diversity of systems and guidelines for best practice has evolved to assess age in adolescents. These tend to involve combinations of history collection, physical anthropometry, and radiographs. ${ }^{3}$ Their lack of uniformity identifies an underlying difficulty: there is no method by which chronological age can be estimated precisely in this age group. Paediatricians in the

\section{Correspondence to: Dr C A Michie, Ealing Hospital NHS Trust, Uxbridge Road, London UB1 3HW, UK; colinm@ easynet.co.uk}

Accepted 18 January 2005
$\mathrm{CH}$, aged 12 years, was taken out of her school in rural Africa one morning, along with her father who taught there. At home she was restrained with her brother and sister while her parents were interrogated and killed. CH was abducted and became one of a number of girls used for sexual favours in the military group. In the next three years she had two live births and a miscarriage. When the leader of the militia disappeared, she was separated from her children and bartered between strangers before being flown to Heathrow Airport. She was accompanied through customs by a guardian who subsequently appeared to have abandoned her on a railway platform in Leeds. CH was found by transport police who put her in touch with the National Asylum Seekers Service (NASS). NASS provided her with a room in a large hostel for adults. There she deteriorated, becoming withdrawn, anxious, and troubled by poor sleep and abdominal pain. When admitted to a local hospital with haematemesis she was found to have a stomach ulcer, gonorrhoea, and malaria. On the fourth day of admission on an adult ward the nursing staff called a paediatrician as they thought she may be a minor. $\mathrm{CH}$ is now in the care of a foster family, receiving appropriate medical and psychological help. 
United Kingdom care for small numbers of individuals in late adolescence and early adulthood in graduate outpatient services, but often have little experience in this area. "Save the Children" and the United Nations High Commission for Refugees recommend clear national procedures involving child experts to deliver safe and dignified age assessments which do not violate human rights. As the application of radiographic reviews may violate such rights, this precludes the use of a set of investigations widely employed in the past.

There is little published research into optimal methods of age assessment, and scant data outside forensic dentistry to show how to achieve more accurate results. ${ }^{2}$ There are clear demonstrations of the inadequacy of the use of any single physical measurement technique, particularly radiographs, whether of wrist, shoulder, teeth, or jaw. Variations between ethnic groups, nutritional state, and socioeconomic status, as well as secular trends in some measures, are too complex to allow the rapid application of any method. Further, the scientifically determined margins of error will frequently make it impossible to determine exactly which side of 18 years an individual may fall. A meeting convened at the Kings Fund, London, in 1999 was used to establish national guidelines recognised by all agencies. ${ }^{4}$ These emphasised the importance of stating the error involved in any age assessment of at least \pm 2 years.

Assessment of most unaccompanied individuals is usually undertaken initially by immigration or police officers. Disputed cases are then referred to the local social services for age assessments. Pressures on all these facilities in terms of time and numbers result in significant numbers of minors being treated as adults by default, despite the "benefit of the doubt" guideline. As an example of the numbers concerned, Hillingdon Social Services covering Heathrow Airport looked after over 600 asylum seeking children under the age of 16 years at the end of 2003 (personal communication). Several strategies have been applied to this problem. The use of a dedicated police officer for child protection, as well as a specific questionnaire for use by staff working in Heathrow's Terminal 3, has improved referral systems. Social Services has developed a specific age assessment tool and has emphasised the importance of specific training. However practices vary significantly across the country and are rarely robust.

\section{PROPOSALS FOR IMPROVEMENT}

The scale and impact of these failures, compounding child abuse, suggest rapid and specific remedies are needed. By developing existing systems, it should be possible to deploy skilled, trained assessors to work at major ports of entry. Such individuals could be social workers experienced with adolescents, accountable to and audited by a child protection team with a paediatric opinion available to them in some form. It would be optimal for them to be financially independent of borough Social Services. With appropriate application of the "benefit of the doubt rule" such reception teams could dispense with the arbitrary nature of a classification system built around a definition of age of 18 years. Nomination of such helpers would allow some control over the processes of age estimation. As Lord Laming stated in the Victoria Climbié case, "The use of eligibility criteria to restrict access to services is not found either in legislation or in guidance, and its ill-founded application is not something I support". ${ }^{5}$ Such flexibility has existing legal support. The Children Leaving Care Act of 2000 provides guidance to local authorities to attend to those leaving care at 18 years of age. In a recent High Court case the Hillingdon Local Authority was charged with providing the full care package owed to asylum seekers after 18 as "looked after" young people ([2003] EWHC 2075).

\section{CONCLUSIONS}

The fairness, legality, and ethical base of any national framework for age assessment has to take into account legal history, jurisprudence, as well as the paediatric wisdom, "What if this were my child?". Although it may be difficult to quantify the inadequacies of the current system, it clearly compounds abuse to a vulnerable group of children. We must do better.

\section{ACKNOWLEDGEMENTS}

The author would like to gratefully acknowledge the guidance, help, and advice given by Barry Jones, Child Protection Officer for Heathrow Airport, Helen Johnson of the Refugee Council, Rajendra Rayan, solicitor with the Refugee Legal Centre, and Dr Donald Bentley, paediatrician.

Competing interests: none declared

\section{REFERENCES}

$1 \mathrm{http}: / /$ www.homeoffice.gov.uk/rds/rf2003.html.

2 Mornstad H, Reventlid M, Teivens A. Validity of four methods for age determination by teeth in Swedish children. Swed Dent J 1995;19:21-130.

3 http://www.doh.gov.uk/public/cla2002.htm.

4 RCPCH. The health of refugee children: guidelines for paediatricians. London: Royal College of Paediatrics and Child Health, 1999.

5 http://www.victoria-climbie-inquiry.org.uk/. 